\title{
Cultural Intelligence and Creativity: The Experience of Trainees Abroad
}

\author{
Silvia Zanazzi ${ }^{1}$ \\ ${ }^{1}$ Sapienza University of Rome, Italy \\ Correspondence: Silvia Zanazzi, Fellow Researcher, Sapienza University of Rome, Italy.
}

Received: April 7, 2017

Accepted: May 12, 2017

Online Published: May 26, 2017

doi:10.5430/irhe.v2n2p33

URL: https://doi.org/10.5430/irhe.v2n2p33

\begin{abstract}
Cultural intelligence (CQ), defined as 'an individual's ability to be effective in situations characterized by cultural diversity' (Ang, Van Dyne, 2008), can be developed and strengthened through experience, education and training. For a number of years, research on cultural intelligence has found important and recurring results for individuals with higher levels of CQ: better cross-cultural adjustment, improved job performance and enhanced personal well-being. More recent works have focused on the relation between cultural intelligence, creativity and innovation, opening new horizons for studies in the field.

In light of these recent developments, the paper explores the link between cultural intelligence and creativity in a specific context: a program for American college students doing their traineeship in Rome, Italy. The research is based on the analysis of field journals written by trainees. While reading and coding them, we looked for 'proofs' of divergent and critical thinking, assuming, based on a literature review, that they are important components of the creative process. Results show that divergent and critical thinking are consistently present in the journals written by trainees who have been positively assessed by their academic tutors and placement supervisors. Critical and divergent thinking, and subsequently creativity, are likely to be higher among individuals who demonstrate interest and openness to the new culture they encounter and are capable not only to describe it, but also to compare it with their own. This re-confirms the importance of cross cultural training to enhance the learning outcomes of a traineeship abroad.
\end{abstract}

Keywords: cultural intelligence, creativity, divergent thinking, critical thinking, traineeships, cross cultural training

\section{Introduction}

Cultural intelligence (CQ), defined as 'an individual's ability to be effective in situations characterized by cultural diversity' (Ang, Van Dyne, 2008), can be developed and strengthened through experience, education and training. Field research has demonstrated that living and working abroad can contribute to 'training' culturally intelligent individuals (Ang, Van Dyne, 2008). More specifically, the role of traineeships abroad in developing cultural intelligence has already been investigated through the analysis of more than a hundred trainees' field journals (Zanazzi, 2010). The findings of this previous study clearly confirmed the positive relation between a traineeship abroad and the development of CQ. Good linguistic skills, or at least motivation and attitude to develop them, was identified as a key factor, together with the availability of cultural training to increase awareness, motivation and knowledge of the host country, the essential 'bricks' of cultural intelligence.

For a number of years, research on cultural intelligence has found important and recurring results for individuals with higher levels of CQ: better cross-cultural adjustment, improved job performance and enhanced personal well-being (Ang, Van Dyne, 2008; Earley, Mosakowski, 2004; Trompenaars, Humpden-Turner, 1998). More recent works have focused on the relation between cultural intelligence, creativity and innovation, opening new horizons for studies in the field (Altememi, Hassouneh, Alkshali, 2015; Livermore, 2011; Maddux, Galinski, 2009).

\section{Theory}

Traditionally, research on intelligence focused on 'academic and cognitive' factors; more recently, the multiple intelligence theory (Sternberg, 1988) investigated non-academic intelligences, emphasizing the capability to adapt to others. Newly recognized forms of intelligence include interpersonal intelligence (Gardner, 1993), emotional intelligence (Goleman, 1995) and social intelligence (Cantor, Kihlstrom, 1985). Each of them assumes that familiarity with culture guides thoughts and behaviors: therefore, these general capabilities might not be sufficient in culturally diverse settings. Differently, cultural intelligence (CQ), a theoretical extension of contemporary 
approaches to the study of intelligence, is defined as the ability to function effectively in situations characterized by cultural diversity (Ang, Van Dyne, 2008). Early and Ang (2003), who introduced CQ for the first time, theorized that it is a multidimensional concept including four dimensions - meta-cognitive, cognitive, motivational and behavioral that are different facets of the overall capability to function and manage effectively in culturally diverse settings.

Meta-cognitive cultural intelligence refers to the mental capability to acquire and understand cultural knowledge; it consists in cognitive strategies that allow individuals to search for new information about novel cultures and process it at a deeper level, consciously questioning their own cultural assumptions. Cognitive intelligence, acquired from educational and personal experiences, reflects general knowledge of norms, practices and conventions in different cultures as well as knowledge of cultural universals, that is common features of all cultures, based on fundamental needs. Motivational intelligence focuses on individual capability to direct attention and energy toward learning about and functioning in intercultural environments; it is a source of drive and facilitates goal accomplishment. Behavioral intelligence is the capability to exhibit appropriate verbal and nonverbal actions when interacting with people from different cultures. It is important to note that CQ is not specific to a particular culture, rather it is specific to particular types of situations, those characterized by cultural diversity (Ang, Van Dyne, 2008).

More recent works have focused on the relation between cultural intelligence, creativity and innovation, opening new horizons for studies in the field (Altememi, Hassouneh, Alkshali, 2015; Livermore, 2011; Maddux, Galinski, 2009). In light of these recent developments, the paper explores the potential link between cultural intelligence and creativity in a specific context: a program for American college students doing their traineeship in Rome, Italy. It is a well established program that offers more than 60 different traineeships for a number of students varying between 70 and 100 per academic year. Traineeships are a non mandatory option, chosen by roughly one third of the students enrolled in the study abroad program; they entail a presence at the placement for a minimum of 120 hours, together with attendance of a weekly seminar. Trainees are required to write field journals, a form of reflective writing that fosters experiential learning by re-processing and interpreting experience (Moon, 2006).

\section{Research Questions}

In order to clearly articulate the research question, it is necessary to 'operationalize' the two core concepts of this work, that is cultural intelligence and creativity.

For cultural intelligence, since the concept is focused on effectiveness, we can use academic tutors' and placements' evaluations as a proxy. I assume that trainees who were evaluated in the A range (Note 1) have actually been effective in culturally diverse environments.

As far as creativity is concerned, I use divergent and critical thinking as proxies, assuming that they are important components of the creative process. In fact, several authors have already made connections between divergent thinking and creativity (Guilford, 1950; Gomez, 2007; Runco and Acar, 2012), as well as between critical thinking and creativity (Adams, 2006; Bailin, 2002; Bonk \& Smith, 1998; Ennis, 1985; Paul \& Elder, 2006; Thayer-Bacon, 2000).

Literature provides different definitions of creativity, divergent thinking and critical thinking. In my study I adopt the following definitions:

\section{Creativity is seen as}

'the process of becoming sensitive to problems, deficiencies, gaps in knowledge, missing elements, disharmonies, and so on; identifying the difficulty, searching for solutions, making guesses, or formulating hypotheses about the deficiencies; testing and retesting these hypotheses and possibly modifying and retesting them; and finally communicating the results' (Torrance, 1965, pp.663-664).

Divergent thinking (Guilford, 1950) refers to the generation of creative ideas by exploring many possible solutions. It is often mentioned 'in opposition' to convergent thinking, which follows a particular set of logical steps to arrive at one solution, considered the only 'correct' solution. By contrast, divergent thinking typically occurs in a spontaneous, 'non-linear' manner: many possible solutions are explored in a short amount of time, and unexpected connections are drawn. Guilford (1950) described the characteristics of divergent thinking as: a) fluency - the ability to produce great number of ideas or problem solutions in a short period of time; b) flexibility - the ability to simultaneously propose a variety of approaches to a specific problem; c) originality - the ability to produce new ideas; d) elaboration - the ability to systematize and organize the details of an idea and carry it out.

Critical thinking includes the component skills of analyzing arguments, making inferences using inductive or deductive reasoning, judging or evaluating, and making decisions or solving problems. The critical thinker is 
described in the literature as someone who is inquisitive in nature, open-minded, flexible, fair-minded, has a desire to be well-informed, understands diverse viewpoints, and is willing to both suspend judgment and to consider other perspectives (Lai, 2011).

At this point, I can articulate the research question referring to the above defined concepts of cultural intelligence, creativity, divergent thinking and critical thinking:

In the reflections by 'culturally intelligent' trainees abroad about their traineeship experiences, is there evidence of divergent and critical thinking, so to suggest an indirect relation between cultural intelligence and creativity? If so, how could we effectively unleash the potential of training programs in order to strengthen this relation and create a virtuous synergy?

\section{Methodology}

The research work presented in this paper is based on the analysis of field journals written by trainees. As a first step, I used several criteria, among which the academic tutor's and the placement's performance evaluations, to select the most 'culturally intelligent' trainees: those who demonstrated to be the most effective in a cross cultural environment. Then, I limited my analysis to their field journals: about 300 pieces, written between 2013 and 2016. From the content analysis of these journals, as well as from direct observation during seminars and feedback provided by placement supervisors, I could gather evidence of divergent and critical thinking. Does this mean that culturally intelligent individuals also possess creativity-relevant skills?

In my work I refer to grounded theory (Glaser \& Strauss, 1967), a methodological approach to qualitative research, where theory is rooted in the data and emerges from it. Grounded theory investigations begin with the raising of generative questions, which help to guide the research, but are not intended to be either static or confining. As the researcher begins to gather data, theoretical core concepts are identified and tentative connections are developed between them and the data. As stated by its founders, grounded theory is a complex iterative process where data collection and analysis go hand in hand, continually informing one another (Glaser \& Strauss, 1967). I use the software NVivo to code texts, as a support for the analysis.

Qualitative research abides by principles of validity and reliability that are very different from those of positivism and quantitative methods. This study respected the principles for validity as described in well established literature on qualitative research (Cohen, Manion, Morrison, 2011). Since qualitative research strives to record the multiple interpretations and meanings given by individuals to situation and events (Cohen, Manion, Morrison, 2011), the notion of reliability in this study is construed as dependability, involving respondent validation, debriefing by peers, trails of evidence, inter-rater agreement on coding and data interpretation (Lincoln and Guba, 1985, Anfara, Brown, Mangione, 2002).

\section{Findings}

As already mentioned in the theoretical introduction, cultural intelligence (CQ) is a multidimensional concept including four dimensions - meta-cognitive, cognitive, motivational and behavioural - that are different facets of the overall capability to function and manage effectively in culturally diverse settings. At first, I had coded all available materials referring to the four dimensions of CQ. Then, I re-coded the materials in search for evidence of divergent and critical thinking, which were found consistently present in the students' reflections, even if in different 'quantity', with a strong prevalence of coding references under critical thinking and a weaker (less than half) presence of coding references under divergent thinking. While critical thinking evidence was mostly found together with proofs of meta-cognitive and cognitive CQ, divergent thinking is more often associated with the motivational and behavioural dimensions.

\subsection{Critical Thinking}

We defined the critical thinker as someone who 'is inquisitive in nature, open minded, flexible, fair-minded, has a desire to be well-informed, understands diverse viewpoints, and is willing to both suspend judgment and to consider other perspectives' (Lai, 2011). These characteristics appear as strictly connected with meta-cognitive and cognitive dimensions of CQ. Below we emphasize, using italic, the areas of potential 'overlapping' between meta-cognitive $\mathrm{CQ}$ and critical thinking, then between cognitive CQ and critical thinking.

\subsubsection{Meta-cognitive CQ and Critical Thinking}

Meta-cognitive cultural intelligence is based on high-level cognitive strategies and deep information processing that help individuals learn about social interaction across cultural contexts (Van Dyne et al., 2012). It consists in cognitive strategies that allow people to search for new information about novel cultures [desire to be well informed] 
and process it at a deeper level [inquisitive], consciously questioning their own cultural assumptions [open minded; understand different viewpoints]. This dimension of cultural intelligence usually emerges slower than the others; in fact, questioning cultural assumptions [open minded; understand different viewpoints] means, first of all, being aware of them. This is usually a discovery that comes with time and constant exposure to cultural differences. Individuals with high meta-cognitive cultural intelligence are conscious of how their own culture influences their behavior and their interpretation of intercultural situations [open minded; understand different viewpoints]. They also know the importance of preparing or planning for intercultural interactions [desire to be well informed] by participating, for example, in cross-cultural training programs. During intercultural interactions, they actively check to see if their interpretations are consistent with the intentions of others [consider other perspectives] (Van Dyne et al., 2012). During internship seminars and in trainees' journals, the meta-cognitive dimension of cultural intelligence emerges in different ways, that can be summarized referring to Van Dyne 'sub-dimensions' of CQ: planning, awareness and checking. Planning is based on thinking deeply about a culture and anticipating what needs to be done in advance of the interaction. It means taking the perspective of culturally diverse others [consider other perspectives] before the intercultural event and anticipating how they might respond to different situations. Reflecting on the actions of others enhances understanding [suspend judgment; consider other perspectives], especially in novel situations (Van Dyne et al., 2012). While planning focuses on anticipatory consciousness, awareness describes the degree to which people are conscious of how cultural aspects of the situation might be influencing personal behavior and the behaviors of others, being careful to suspend judgments until enough information is available for making sense of intercultural interactions [open-minded; desire to be well-informed; suspend judgment; consider other perspectives]. Awareness also includes being proactive and taking the perspective of culturally diverse others [consider other perspectives]. All in all, it translates into the capability of making sense of self, others, and the situation in specific cultural contexts (Van Dyne et al., 2012). The third sub-dimension, checking, involves comparing expectations and actual occurrences during inter-cultural interactions. It includes evaluating the extent to which assumptions and expectations are consistent with how culturally diverse others behave in real situations [inquisitive; fair-minded; suspend judgment; consider other perspectives], and adjusting knowledge structures accordingly (Van Dyne et al., 2012). Together, the three sub-dimensions of meta-cognitive cultural intelligence emphasize the dynamic nature of cultural intelligence: they represent thinking in advance about people and situations in intercultural settings, challenging rigid reliance on culturally-bounded habits and thinking and adapting mental models and strategies [open-minded; flexible; consider other perspectives] so they are more likely to achieve desired outcomes in intercultural interactions (Van Dyne et al., 2012).

Below I provide some examples of content coded under both critical thinking and meta-cognitive CQ. As described previously, meta-cognitive cultural intelligence is the development of cognitive strategies that allow people to search for new information about novel cultures and process it at a deeper level. Similarly, thinking critically means being inquisitive, open minded, flexible, having a desire to be well informed and understand different viewpoints:

(1) I have learned that before coming to a country, I should do more research as a starting point, so I can kind of know what to expect. I know that the internet doesn't always paint the most accurate picture, but it serves as a good starting point. After arriving, I will make an effort to engage in conversation about the culture and preferences of the place to allow myself to gain more context for future reference. Integrating myself into the culture by spending time with people outside of only work will also allow me to adjust to the high context culture (Note 2) (Trainee's journal, 2015).

(2) My work environment is more focused on relationship first and then task [...]. This was new to me because I am used to going into work and getting the job done. I have never gotten to know my co-workers too well, especially my boss. In my other traineeships I have talked to my boss, but never on a personal level, it was all business, but here I developed a relationship with my boss and the others in my work environment which was new to me. At first I was uncomfortable getting to know my boss, because in the States most trainees barely talk to the head boss at all. However, I successfully coped with the differences and it did not serve as a problem for me during my traineeship. I realized that a relationship had to be built in order for me to have a successful time at work and I put in the effort to get to know my boss and colleagues and to build trust. Ultimately, I am glad it was relationship oriented (Note 3) and wish it was more like that in the States. This particular characteristic of my work environment helped me develop my social skills in a business setting. I think forming a relationship helps, and even if in the States it is more task oriented, I am going to try to incorporate more relationship, even if it is only a little, because I think it helps build 
trust and make for a more enjoyable work environment. This will definitely be a helpful skill to have and use in my future (Trainee's journal, 2014).

(3) Something important that I learned about myself this semester has been how I respond to conflict, and how equipped I am to mediate between disagreeing sides in a tense situation. Before coming abroad, I never really had to face conflict head-on. I've always been very indirect (Note 4) and did everything in my power to prevent a conflict from arising in the first place. If a disagreement ever occurred, I would avoid it at all costs; even if that meant compromising something in which I believed [...]. After working with my supervisor and experiencing some tense moments of conflict, I realized that backing down is not always the best way to handle disagreements. Although confrontation is certainly undesirable, I realized that I am capable of standing up for myself in a very respectful and calm manner [...]. Part of handling conflicts with maturity entails being able to look past previous disagreements. Although this particular conflict was not enjoyable at the time, I can clearly see how it contributed to my development as an employee, and my ability to conduct myself in a mature manner. I'm slowly but surely becoming less afraid of confrontation, and less sure of my own ability to handle it (Trainee's journal, 2014).

These three quotes have a lot of common characteristics. First of all, the authors reflect on their own cultural assumptions, or simply on their habits, with a critical approach, acknowledging that they are not the only way to do things, rather they are the product of the environment and culture they grew up in: here, the trainees show the ability to 'detach' that is necessary to be able to analyze any situation. Secondly, the authors refer to articles and literature on cultural differences (Note 5), citing relevant concepts (high context culture, task orientation, indirectness ...) and explaining them: here, they show their 'desire to be well informed' and 'understand different viewpoints'. Finally, they all express their availability to 'consider other perspectives', they comment on how such perspectives will impact on their future, in some cases they even acknowledge that the new way of doing things is more effective or simply more enjoyable for them. All these attitudes well describe a trainee who is 'inquisitive in nature, open-minded, flexible, fair-minded'.

\subsubsection{Cognitive CQ and Critical Thinking}

The cognitive dimension of cultural intelligence refers to an individual's knowledge about institutions, norms, practices and conventions in different cultural settings [inquisitive; desire to be well informed]. Research identifies both culture-general and context-specific knowledge as important for the development of cultural intelligence. The first is defined as knowledge of the universal elements that constitute a cultural environment, the latter refers to learning about specific aspects of a host country (Van Dyne et al., 2012). Evidence of the cognitive dimension of cultural intelligence, both in its culture-general and context-specific aspects, is immediately available when analyzing data.

Below I provide some examples of content coded under both critical thinking and cognitive CQ:

(4) With regards to the cultural differences discussed in the seminar class, one of the orientations that I could identify as a struggle at the job was views of time management: short term versus long term goal. I think coming from my culture I like to see things happening right away; short term results from my work. My Italian supervisor was definitely more long-term oriented (Note 6). She didn't seem to want to hop onto opportunities as much as I did, and was more about the big picture. At first this was really hard for me because I felt like she was missing out on a lot of opportunities that could help out her company. As I observed more, I learned to just let her pick what she wanted and listen to her reasoning for why. I didn't always agree with the choices she made and it was hard for me to understand her decisions. In the end, I think it was good for me to be put in situations that made me think of what will happen in the long term and just not short term (Trainee's journal, 2014).

(5) A characteristic that I noticed in my work environment is that it was very collectivistic instead of individualistic (Note 7). Everyone works together as a team towards a common goal, instead of one person trying to outshine everyone else and get ahead. It was important for there to be unity within the group and to make sure everyone was on the same page as one another, rather than everyone doing their own thing and own work. I feel as though in the States everyone tries to just fend for themselves, so they can get noticed by the boss in hopes of getting offered a job or standing out and being remembered for a job after graduation. Instead of working for the group, everyone seems to work for themselves, but that is not how it worked at my placement here. My 
work environment was focused on it being a group effort. At first it was somewhat difficult for me to work that way, because I am so used to working individualistically, however I adapted my habits to be more successful in my work environment. One way I did that was by realizing that although I may be able to get a lot of work done by myself and maybe impress my boss, I realized that teamwork is a very good trait to have. I will use this in my future endeavours because sometimes you need to work individually, but a lot of the time you have to work with a team (Trainee's journal, 2013).

(6) Americans make eating difficult. Because we are a melting pot country of countless different cultures and ethnicities, our culinary choices are influenced by flavors from all over the world. It is possible, especially when living in a city like I do, to eat a different type of food every day. It is easy to become spoiled by the readily available types of cuisine so that we become bored when eating the same type of food more than a few times a week, or even less. Another consequence of our obsession with interesting and diverse food is our need to ship that interesting and diverse food from all corners of the earth. This means that food has to be preserved to make it across the country or ocean and therefore is not fresh. Our food is too far away from our table. I am a trainee at an Italian restaurant and cooking school. Italians make eating simple. In Italy, we only eat the food that can be grown or raised near to us. We only eat food that is fresh and in season. And we use these ingredients to cook traditional recipes that have been in the culture for generations. They are not fancy and don't require any rare spices or fancy kitchen equipment. They are easy to make and because the ingredients are fresh, they are delicious and nutritious [...]. Italians don't need exotic food to be satisfied. That's not only because the food is delicious but because that food also comes with the company of family and friends. There is seldom a reason to eat a meal alone. Italian culture is not only based on food but it's based on the way that you eat food. You eat food in several smaller portions over a longer period of time and spend most of that time talking and laughing with loved ones. Differently, Americans are too busy to eat a meal with their loved ones every day, especially students like me. We see eating as a primal need that must be satisfied, preferably with good food, and then we need to move on with our days (Trainee's journal, 2013).

Again, we can find common themes in these three quotes. As far as culture-general knowledge is concerned, trainees seem to reflect on the readings provided by the seminar instructor about cultural differences in the workplace and they often comment in their field journals applying the concepts to their experience at the placement. Context-specific knowledge also emerges very clearly in trainees' writings, resulting from dedicated seminar sessions and readings (Note 8), but also from independent research. While in the previous quotes the trainees focused on themselves and their cultural assumptions, here they mostly observe and analyze the local context, making comparisons with their work experience and life in the US. From this evidence, again, we observe trainees who appear 'inquisitive in nature, open-minded, flexible, fair-minded'.

\subsection{Divergent Thinking}

We defined divergent thinking as the process to generate ideas by exploring many possible solutions, occurring in a spontaneous, non linear manner, and characterized by fluency (great number of ideas or solutions in a short time), flexibility (a variety of approaches to a specific problem), originality (new ideas) and elaboration (systematization and organization of details). A large part of the content coded under 'divergent thinking' was also coded under 'motivational CQ' or 'behavioural CQ'.

\subsubsection{Motivational CQ and Divergent Thinking}

The motivational dimension of cultural intelligence is the capability to direct attention and energy toward learning about intercultural environments and, consequently, functioning well in them. This often seems the strongest dimension for many trainees, at least at the beginning of their experience. In many cases, motivation seems to compensate for weaknesses in other areas, especially in the cognitive dimension. Often trainees seem to find their motivation to integrate in the new work environment through a process of divergent thinking: finding themselves initially 'lost' in environments where things function differently, and not understanding how they function yet, they activate their minds and hearts to devise many possible solutions to everyday issues and problems. This often translates into stronger motivation to learn and new approaches to problem solving. Divergent thinking might also foster critical thinking, when a stronger motivation leads to a stronger will to be inquisitive, flexible and open minded. 
Below I will share some examples of content coded under 'divergent thinking' and at the same time under 'motivational CQ' in trainees' field journals. As previously stated, motivational cultural intelligence is the capability to direct attention and energy toward intercultural learning. Divergent thinking is the process of idea generation by exploring many possible solutions occurring in a spontaneous manner:

(7) I gained a sense of confidence in my teaching abilities. Prior to my traineeship, I was very nervous to make mistakes when I was doing some student teaching during the past semester. However, through this traineeship, I have learned that I am capable of a lot more than I knew previously, and I feel now very motivated to pursue a career in teaching. The other teachers at the kindergarten pushed me to take risks with the children and sometimes allowed me to plan activities for the children to do. Because the teachers had confidence in me, I, in turn, gained confidence in myself and motivation. As a teacher, it is highly important to be able to be flexible in the classroom. While it is true that lesson planning is important to daily structure, it is impossible to plan for each and everything that could happen throughout the day. By taking so many risks and gaining a sense of independence and flexibility in Italy, I have confidence that I will be able to adapt to any situation that may happen during a carefully planned lesson in my future career (Trainee's journal, 2014).

(8) Thanks to my traineeship, I now have the skill sets to throw things together with no time at all. I've learned to take a step back, breath and realized I did my best under the circumstances and be proud of myself simply for trying. I've learned that sometimes not everything has to be planned and I can rely on my own skills to come through when I need them. I've also learned that sometimes when you don't have a plan other great things come out of it (Trainee's journal, 2013).

(9) Alone in a foreign city, not able to speak the local language and with no news on where I was going to do my traineeship, made the words, "If you don't get lost, there's a chance you may never be found" a reality. For about a full day I was completely regretting coming to Rome. I felt as if I had no motivation to do this. I sat in my room talking with friends from home wishing I could be there when I had an epiphany: there is no way I am going to be miserable while I am in probably the most famous historical city in the world. There are people who would die for the opportunity I am given to live here, let alone be able to work here. This thought completely changed my mind set and at the perfect time as well because the next day I was told that I would be working for a professional tour company. I started feeling very motivated to start this new experience. Although the first week at my job went very slow, my new open-minded approach to this trip helped me get through it without much trouble. I was not assigned too many tasks until about halfway through when my fellow trainee and I were assigned the task to edit the old website and begin to write the new one. This proved to be a very difficult task because there were about 50 different tours that each had a specific description written in broken English and filled with grammatical errors. The supervisor depended on us a lot more than I thought she was going to. Even down to the last day at work, she sat us down and watched us write while guiding us through each tour. Once the job had purpose, there is nowhere else I would have rather worked than with her (Trainee's journal, 2014).

Reading these three quotes, we can imagine the trainees feeling 'lost' in a new situation, without any reference point, then taking 'a step back' and reflecting on the cultural differences, or simply the specific circumstances, that make them feel uneasy. This moment of 'pause' is when ideas come that are new and different from their culturally ingrained knowledge or habits. The episodes are then re-elaborated from a distance and a 'learning moral' is given to each story.

\subsubsection{Behavioural CQ and Divergent Thinking}

The behavioral dimension of cultural intelligence is the capability to exhibit appropriate verbal and nonverbal actions when interacting with people from different cultures. This behavioral flexibility is critically important in intercultural contexts because people do not have direct access to thoughts, feelings, and motivations of others. Instead, they must rely on what they see, hear, and infer from verbal, vocal, facial, and bodily expressions (Van Dyne et al., 2012). Those with high behavioral cultural intelligence overcome the natural human tendency to rely on habits, showing instead the capability to adapt verbal and non-verbal behavior (Van Dyne et al., 2012). Behavioral CQ can be seen as deriving from previous reflection, a sort of 'flexible thinking' that allows trainees to leave their habits behind in a culturally diverse environment, choosing among many different alternative behavioral options the one(s) that seem 
more suitable for the context and, at the same time, more natural for themselves. Trainees seem not to follow any set of 'behavioral rules', rather they observe the context, observe others, assess alternatives and make a final choice. There is no correct solution, as in any divergent thinking process, rather there are many unique creative solutions that can be equally effective and culturally sensitive, at the same time.

Below I will share some examples of content coded under 'divergent thinking' and at the same time under 'behavioral CQ' in trainees' field journals:

(10) For my traineeship, I taught English as a second language to a group of refugees. This refugee course continually taught me to stop comparing my own educational background and teaching experience to the refugees, which even led me to restructure my teaching method. Since we did not teach from a book and have had no formal teaching training, personal experience and some online guides were they only tools we went by. Yet week after week I learned about their learning style and how external factors affect their learning. I learned as the weeks progressed that as a refugee teacher, you never know [...]. I think our classroom's fluctuation succinctly represents the fluctuation in the refugees' lives - an experience neither of us teachers had experienced before [...]. It was harder for us to track the individual student's progress, which ultimately is an objective of a language course. Yet here we had to take a step back and truly evaluate the goals for this class versus the goals of a "typical" class. Homework, assessments, group projects, speaking and comprehension ability, level improvement, and attendance/student involvement are all factors or tools that typically measure the success of a language class or of an individual student. For our class, we had to leave a lot of these tools at the door. This reminded me of the Montessori model of education, focused on empowerment through education, and the idea that giving up on "bad" students is the worst thing the educational system can do. In our case, empowerment through education, and teaching in novel, interactive ways like Montessori did prove to be successful. The use of hands-on demonstrations, writing on the whiteboard, interactive mock exercises (going to doctor, booking a plane ticket, shopping for food), role-playing dialogues with scripts, songs, videos, and games were some of the most fruitful teaching methods we used [...]. As each week passed, we learned to put less on the powerpoint and include more interactive activities; if time runs short, which it often does because of their late arrival, you should cut the amount of vocabulary but not the game [...].A goal of our class was not necessarily to have them learn vocabulary, but to have a supportive environment. To give continuity is a hidden goal for ESL: the same teachers, the good snacks, and the supportive encouragement are necessary when their life is in flux (Trainee's field journal, 2016).

(11) I chose this placement particularly because it was an environment in which I expected to be comfortable. They are strong women running a business in the art community. I expected to be surrounded by people similar to those I know back home, and to share many of the same thoughts and interests. At the beginning, I didn't quite realize how much the cultural difference between us would affect my level of comfort. I often times had nothing to do which was a source of great frustration. It wasn't occasional that I felt I was wasting my ten hours a week there, and that maybe this internship wasn't for me. However, it turns out I was very productive during those hours with "nothing to do." I spoke Italian, and observed the women working there. I looked at the style of art they sold, which is unlike much of what I seen in the States. I made coffee for the other ladies and went on cigarette runs. All of this nothing time was actually time I spent experiencing my surroundings, and the hours added up to an understanding of the greater social context, not only of my placement, but of Rome and Italy in general. This understanding put my mind at ease, and with a new found comfort I found I was able to contribute much more to the business - both professionally and personally (Trainee's journal, 2013).

(12) People put their emotions into their work and you could tell peoples moods and attitudes towards things; they did not hide their feelings. One example of this was when one of the workers in the building was having a bad day, my boss put a pause on her work and talked with the other worker about their day and tried to cheer them up. She put her work on hold, so the co-worker could express her feelings and deal with them before she got back to work. This was new to me, because I am very neutral (Note 9) when I am at work and in most situations. I usually only show emotion to my family and very close friends because I am a very private person, however I was able to adjust and find a comfortable middle ground. I did this by making sure I showed enthusiasm and 
engaged in conversation with my co-workers. I let them know I cared, without having to get too personal with details about my life. I made sure I still focused on work, but also focused on the feelings of my co-workers by being aware of people's moods and acting accordingly to them (Trainee's journal, 2015).

In these quotes, the focus is more on the trainees' behaviour, rather than on their motivation. We can imagine each of them facing a practical problem and coming up with his/her own personal, yet culturally sensitive solution. Here, trainees demonstrate behavioural flexibility: they have to adapt to situations that are different from their habits and previous experience. In spite of a feeling of uneasiness at first, they end up being 'effective' and satisfied in the new context.

\section{Discussion}

As I explained in the introduction, traineeships are a non-mandatory option for American college students participating in a well established study abroad program in Rome. They are chosen by roughly one third of the students at the place of a course; they entail a presence at the placement for a minimum of 120 hours, together with attendance of a 20-hour seminar, in which nearly half of the time is spent for culture-general knowledge and cross cultural training, while the other half is focused on some context-specific relevant topics. In addition to attending the seminar, trainees are required to do some readings and to write weekly field journals, a form of reflective writing that fosters experiential learning by re-processing and interpreting experience (Moon, 2006).

Cross cultural training is based on well-established literature concerning cultural analysis and cultural differences in the workplace. In particular, the works by Edward Hall $(1959,1966,1976)$, Harry Triandis $(1972,1995)$ and, more recently, Fons Trompenaars \& Hampden-Turner (1998) and Gert Hofstede (2001), are important point of references.

Trainee's quote 1, for example, refers to the concept of high context culture, introduced by Hall as opposed to that of low context culture. High context refers to societies or groups where people have close connections over a long period of time. Many aspects of cultural behavior are not made explicit, because most members know what to do and what to think from years of interaction with each other. Low context refers to societies where people tend to have many connections, but of shorter duration or for some specific reason. In these societies, cultural behavior and beliefs may need to be spelled out explicitly so that those coming into the cultural environment know how to behave. As a consequence, in a higher-context culture, many things are left unsaid, letting the culture explain. Words and word choice become very important in higher-context communication, since a few words can communicate a complex message very effectively to an in-group (but less effectively outside that group), while in a low-context culture, the communicator needs to be much more explicit and the value of a single word is less important (Hall, 1976).

During the seminar, the instructor uses the Cultural Analysis Study Abroad Toolkit (Mendez, 2010) based on literature in the field of cross cultural psychology and management. It is a brief and well organized 'manual', customized for study abroad programs and traineeships, in which the author offers 'a set of tools to help an investigator establish cultural self awareness, recognize differences from his/her own preferences in a new environment, predict challenges and overcome difficulties' (Mendez, 2010). By observing human behavior, written expression and physical aspects of a new environment, the trainees can identify cultural features that characterize the environment they work (and live) in, creating a multi-parameter cultural profile for it. The features are expressed 'as two ends of a continuum, with each end representing a way of thinking that, while reasonable and appropriate to its own system, conflicts with that at the other end' (Mendez, 2010) (Note 10). In the field journals, written by trainees, as well as in the class discussions and presentations, I found plenty of references to the cultural features and strong evidence of critical thinking and divergent thinking connected to them. In the previous paragraphs, for example, Trainee's quote 2 refers to the parameter relationship/task, describing 'the amount of weight given to logical arguments compared to interpersonal relationships' (Mendez, 2010). In relationship oriented cultures, people interact and make decisions based on personal relationships, while in task oriented ones the logic of opportunity prevails. Trainee's quote 3 refers to the parameter indirectness/directness, describing 'the way communication is delivered with respect to maintaining relationships and managing conflict'(Mendez, 2010). In indirect cultures, the goal of communication is the preservation of relationships, while in direct ones the goal is the mere transfer of facts and information. Trainee's quote 4 refers to the parameter short term/long term, describing 'attitudes towards time and its implications for the development of strategy and creation of relationships' (Mendez, 2010). In short-term cultures, present and future are the focus, strategy is based on the near term and relationships are developed quickly to take advantage of opportunities, while in long-term cultures past history and tradition are the focus, strategy is based on the preservation or recreation of past success, relationships are developed slowly to ensure success over time. Trainee's quote 5 refers to the parameter individualism/collectivism, describing 'attitudes towards who take 
responsibility for work and decisions and who is rewarded for their outcomes'(Mendez, 2010). In individualist cultures, work is divided into tasks to be carried out by individuals who receive credit or blame for their outcome, while in collectivist cultures projects are undertaken by teams, which are then evaluated as such. Finally, trainee's quote 12 refers to the parameter neutral/expressive, describing 'the degree of emotion conveyed in interaction'(Mendez, 2010). In neutral cultures, feelings and emotions are not made obvious in interaction, while in expressive cultures emotions are allowed to show and to interfere with the executions of duties and in the decision making process.

Reading field journals, one clearly understands that meeting in class for the seminar and sharing experiences helps students, first of all, to become aware of their ethnocentrism. Starting from there, students learn how to recognize their own cultural assumptions. Then comes the ability to recognize cultural differences, critical thinking to understand them and divergent thinking to find solutions in order to adapt effectively to the new context. We could say that critical thinking and divergent thinking, crucial elements of a creative process, are also the pillars for the development of cultural intelligence, that is the ability to be effective in a culturally diverse context. Cultural intelligence and creativity could then be seen as two sides of the same coin, with traineeship abroad, completed by cross cultural training, as an effective 'strategy' to enhance both CQ and creativity-relevant skills. The traineeship seminar has a mix of culture-general and context-specific learning goals. While the seminar instructors often have a hard time engaging students in class activities, in our research the seminar proved to be an essential factor for learning and, specifically, for the development of trainee's cultural intelligence, critical thinking and divergent thinking. In fact, the large majority of cultural observations in field journals and class presentations are related to inputs given in class and then autonomously re-elaborated during field experience. The class turns out to be very important also for the motivational dimension of cultural intelligence. Sharing experiences means knowing that others are noticing the same differences, finding the same obstacles, having the same hard time adjusting. It also means learning how others are tackling with the same problems and being able to 'brainstorm' on how to solve them.

\section{Conclusion}

Divergent and critical thinking, important components of the creative process, are consistently present in the journals written by trainees who have been positively assessed by their academic tutors and placement supervisors. The findings also show that critical and divergent thinking, and subsequently creativity, are likely to be higher among individuals who demonstrate interest and openness to the new culture they encounter and are capable not only to describe it, but also to compare it with their own, by articulating similarities and differences. This re-confirms the importance of cross cultural training to enhance the learning outcomes of a traineeship abroad, possibly fostering positive synergies between cultural intelligence creativity.

I'd like to conclude my paper with a quote by a trainee that, in my opinion, effectively subsumes the kind of 'enrichment' brought in a young mind by the experience of living and working abroad:

(11) In order to best reflect upon my experience, I would like to use the first stanza of a famous Dickenson poem "The Brain--is wider than the Sky--" that goes as follows:

The brain is wider than the sky,

For, put them side by side,

The one the other will include

With ease, and you beside.

As with the majority of Dickinson's poems, it is rather philosophical in nature. In it, she begins by telling us that the brain is wider than the sky. Physically speaking, the brain is very small compared to the vast sky. However, we must use our imagination to place the two side by side, as she instructs us to do in the next line. Here, we understand that, figuratively speaking, the brain is wider than the sky because we can envision the sky within our brains. We can see everything inside of our heads. This is similar to the mind-set that I walked into at my placement. My placement is a small organization with big goals. Every person who works there has their own project on grand and important matters [...]. They understand the power of envisioning something grand and realizing it through sheer hard work [...]. My colleagues were among some of the smartest individuals that I have met. I was forced to change the ways I worked on things and behaved because of them [..]. At first, I found the work rather difficult and would become stressed if something was not going how I expected it to go. I soon realized though that this wasn't the most effective way to accomplish what I wanted to do. I learned that sometimes you need to relax and even if something doesn't go as you expected, it doesn't mean that you are doing a bad job 
[...]. My experience taught me skills and knowledge that will be useful in the future. I was placed into an environment that was not the most comfortable. Many people did not speak English and, at first, I felt very secluded at the organization. As time went by and the more work accomplished, the more comfortable and motivated I began to feel. I had to adapt to new situations and, as a result, I learned new things about myself. Nothing is ever exactly how you imagine that it will be. I believe this is a good thing and forces you to develop as a person (Trainee's journal, 2014).

\section{References}

Adams, K. (2006). The sources of innovation and creativity. Washington, DC: National center on education and the economy.

Altememi, A. F., Hassouneh, I. A., \& Alkshali, S. J. (2015). The Relationship between Creative Capabilities and Cultural Intelligence: Field Study of Amman's Five-Star Hotels. International Journal of Business and Management, 10(12), 103-115.

Anfara, V. A., Brown, K. M., \& Mangione, T. L. (2002). Qualitative analysis on stage: making the research process more public. Educational Researcher, 31(7), 28-38.

Ang, S., \& Van, D. L. (2008). (edited by) Handbook of cultural intelligence. Theory, measurement and applications. New York: M.E. Sharpe.

Bailin, S. (2002). Critical thinking and science education. Science \& Education, 11(4), 361-375.

Bonk, C. J., \& Smith, G. S. (1998). Alternative instructional strategies for creative and critical thinking in the accounting curriculum. Journal of Accounting Education, 16(2), 261-293.

Cantor, N., \& Kihlstrom, J.F. (1985). Social intelligence: the cognitive basis of personality. Review of Personality and Social Psychology, 6, 15-33.

Cohen, L., Manion, L., \& Morrison, K. (2011). Research methods in education. London: Routledge.

Earley, C., \& Mosakowski, E. (2004, October). Cultural Intelligence. Harvard Business Review, 139-146.

Early, P. C., \& Ang, S. (2003). Cultural Intelligence: Individual Interactions across Culture. Stanford Business Books, Stanford.

Ennis, R. H. (1985). A logical basis for measuring critical thinking skills. Educational Leadership, 43(2), 44-48.

Gardner, H. (1993). Frames of mind, the theory of multiple intelligences. New York: Basic Books.

Glaser, B., \& Strauss, A. (1967). The discovery of Grounded Theory: strategies for qualitative research. Hawthorne. New York: Aldine de Gruiter.

Goleman, D. (1995). Emotional intelligence. New York: Bantam.

Gomez, G. J. (2007). What Do We Know About Creativity? Journal of Effective Teaching, 7(1), 31-43.

Guilford, J. P. (1950). Creativity. American Psychologist, 5(9), 444-454.

Hall, E.T. (1959). The silent language. New York: Doubleday.

Hall, E.T. (1966). The hidden dimension. New York: Doubleday.

Hall, E.T. (1976). Beyond culture. New York: Doubleday.

Hofstede, G. (2001). Culture's consequences. Comparing values, behaviours, institutions and organizations across nations. Londra: Sage.

Lai, E. R. (2011), Critical thinking: a literature review. Pearson's Research Reports

Lincoln, Y. S., \& Guba, E. (1986). Naturalistic Inquiry. Beverly Hills, CA: Sage.

Livermore, D. (2011). Cultural intelligence and creativity. Management.Issues. Retrieved from www.management-issues.com

Maddux, W.W., \& Galinski, A.D. (2009). Cultural Borders and Mental Barriers: The Relationship between living abroad and creativity. Journal of Personality and Social Psychology, 96(5), 1047-1061.

Mendez, D. (2010). Cultural Analysis Study Abroad Toolkit. CIBER, The University of Texas at Austin

Moon, J. (2006). Learning Journals. A handbook for reflective practice and professional development ( $2^{\text {nd }}$ ed.). London: Routledge

Paul, R. W., \& Elder, L. (2006). Critical thinking: The nature of critical and creative thought. Journal of 
Developmental Education, 30(2), 34-35.

Runco, M. A., \& Acar, S. (2012). Divergent thinking as an indicator of creative potential. Creativity Research Journal, 24(1), 1-10.

Sternberg, R. (1988). The Triarchic Mind: A New Theory of Intelligence. NY: Viking Press

Thayer-Bacon, B. J. (2000). Transforming critical thinking: Thinking constructively. New York, NY: Teachers College Press.

Torrance, E. P. (1965). Scientific views of creativity and factors affecting its growth. Daedalus, 94(3), 663-681.

Triandis, H. (1972). The analysis of subjective culture. New York: Wiley.

Triandis, H. (1995). Individualism and collectivism. Boulder: Westview Press.

Trompenaars, F., \& Hampden-Turner, C. (1998). Riding the waves of culture. Understanding diversity in global business. London: McGraw Hill.

Van Dyne, L., Ang, S., Yee Ng, K., Rockstuhl, T., Ling Tan, M., \& Koh, C. (2012). Sub-dimensions of the Four Factor Model of Cultural Intelligence: Expanding the Conceptualization and Measurement of Cultural Intelligence. Social and Personality Psychology Compass, 6(4), 295-313.

Zanazzi, S. (2010). Sviluppo dell'intelligenza culturale. Case study: il programma tirocini del consorzio IES. Rivista della Società Italiana di Ricerca didattica, 1/3. Fisciano: SIRD.

\section{Notes}

Note 1. Trainees at the end of the program receive a final evaluation using the US grading system (A: excellent; B: good; C: adequate; D: unsatisfactory; F: fail). The evaluation considers several aspects, concerning the trainee's performance at the placement and his/her participation in the weekly seminar, including field journals and class presentation.

Note 2. High context, a concept introduced by Edward Hall, refers to societies or groups where people have close connections over a long period of time, as opposed to low context societies where people tend to have many connections, but of shorter duration or for some specific reason. While in a higher-context culture many things are left unsaid, letting the culture explain, in a low-context culture the communicator needs to be much more explicit (Hall, 1976).

Note 3. In relationship oriented cultures, people interact and make decisions based on personal relationships, while in task oriented ones the logic of opportunity prevails (Mendez, 2010).

Note 4. In indirect cultures, the goal of communication is the preservation of relationships, while in direct ones the goal is the mere transfer of facts and information (Mendez, 2010).

Note 5. The seminar instructor uses the Cultural Analysis Study Abroad Toolkit (Mendez, 2010) based on established literature in the field of cross cultural psychology and management. In paragraph 5 this will be explained in details.

Note 6. In short-term cultures, present and future are the focus, strategy is based on the near term and relationships are developed quickly to take advantage of opportunities, while in long-term cultures past history and tradition are the focus, strategy is based on the preservation or recreation of past success, relationships are developed slowly to ensure success over time (Mendez, 2010).

Note 7. In individualist cultures, work is divided into tasks to be carried out by individuals who receive credit or blame for their outcome, while in collectivist cultures projects are undertaken by teams, which are then evaluated as such (Mendez, 2010).

Note 8 . The seminar instructor dedicates some of the contact hours to context-specific sessions whose contents are specifically targeted to trainees' needs.

Note 9. In neutral cultures, feelings and emotions are not made obvious in interaction, while in expressive cultures emotions are allowed to show and to interfere with the executions of duties and in the decision making process (Mendez, 2010).

Note 10. The 8 cultural parameters described in the Toolkit are: achievement/birthright approaches to status; universalist/particularist attitudes towards authority; relationship/task attitudes towards accomplishing goals; individualist/collectivist approaches to responsibility and reward; short-term/long-term orientation to strategy; indirect/direct methods of dealing with conflict; neutral/expressive conveyance of emotions; schedule/flow oriented approaches to time management. 